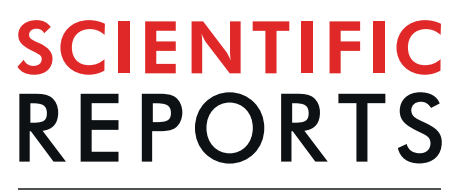

natureresearch

\title{
OPEN Impedance spectroscopy for in situ and real-time observations of the effects of hydrogen on nitrile butadiene rubber polymer under high pressure
}

Received: 10 June 2019

Accepted: 29 August 2019

Published online: 10 September 2019

\author{
Jae Kap Jung ${ }^{1}$, Sang Koo Jeon ${ }^{1,2}$, Kyu-Tae Kim ${ }^{3}$, Chang Hoon Lee ${ }^{4}$, Un Bong Baek ${ }^{1}$ \& \\ Ki Soo Chung ${ }^{5}$
}

Nondestructive impedance spectroscopy (IS) was developed and demonstrated to detect the effects of hydrogen on nitrile butadiene rubber exposed to hydrogen gas $\left(\mathrm{H}_{2}\right)$ at high pressures up to $10 \mathrm{MPa}$. IS was applied to obtain an in situ and real-time quantification of $\mathrm{H}_{2}$ penetration into and its desorption out of rubber under high pressure. The diffusion coefficients of $\mathrm{H}_{2}$ were also obtained from the time evolution of the capacitance, which were compared with those obtained by thermal desorption gas analysis. The in situ measurements of the capacitance and the dissipation factor under various pressures during cyclic stepwise pressurization and decompression demonstrated the diffusion behaviour of $\mathrm{H}_{2}$, the phase of the rubber under high pressure, the transport properties of $\mathrm{H}_{2}$ gas, and the physicochemical interaction between $\mathrm{H}_{2}$ and the rubber. These phenomena were supported by a COMSOL simulation based on the electric current conservation equation and scanning electron microscopy (SEM) observations.

Hydrogen gas $\left(\mathrm{H}_{2}\right)$ is expected to be a future clean-energy source to mitigate global warming and the exhaustion of fossil fuels. The use of $\mathrm{H}_{2}$ as an energy carrier requires safe materials to be used in the $\mathrm{H}_{2}$ infrastructure ${ }^{1-3}$. To satisfy this safety requirement, the embrittling effects of $\mathrm{H}_{2}$ exposure have been studied in steel, stainless steel, aluminium, and alloys ${ }^{4-8}$.

However, many kinds of rubber polymers are used as sealants in $\mathrm{H}_{2}$ environments: polytetrafluoroethylene (PTFE) is used as a sealant in mechanical compressors, and nitrile butadiene rubber (NBR), ethylene propylene diene monomer (EPDM), and fluoroelastomer (FKM) rubbers are used as sealants and gaskets in valves and pipelines ${ }^{9}$. Research on rubber polymers used for gas sealants and liners at the $\mathrm{H}_{2}$ station has focused on understanding the origin of explosive failure by decompression and the swelling behaviour of $\mathrm{O}$-ring rubber under high-pressure $\mathrm{H}_{2}{ }^{10-12}$. Research on how $\mathrm{H}_{2}$ affects the physical properties and morphology after pressurization and decompression has been conducted, but in situ measurements during pressurization and decomposition under high pressure have rarely been performed.

In this study, by using impedance spectroscopy (IS) to measure the capacitance and the dissipation factor (DF), we performed in situ, real-time monitoring of the dynamic macroscopic behaviour of the penetration of the $\mathrm{H}_{2}$ molecule into $\mathrm{O}$-ring rubber and its desorption from the rubber during the processes of pressurization and decompression under high-pressure $\mathrm{H}_{2}$ gas. The results of the impedance measurement for NBR at various pressures and exposure times to $\mathrm{H}_{2}$ gas were analysed. The quantities considered include $\mathrm{H}_{2}$ diffusion, interfacial polarization, plasticization, permeation properties, and the physicochemical interaction between $\mathrm{H}_{2}$ and the

${ }^{1}$ Center for Materials and Energy Measurement, Korea Research Institute of Standards and Science, Daejeon, 34113, Korea. ${ }^{2}$ Department for Safety Engineering, Pukyong National University, Busan, 48513, Korea. ${ }^{3}$ Center for Electromagnetic Metrology, Korea Research Institute of Standards and Science, Daejeon, 34113, Korea. ${ }^{4}$ Department of Biochemical and Polymer Engineering, Chosun University, Gwangju, 61452, Korea. ${ }^{5}$ Department of Physics, and The Research Institute of Natural Science, Gyeongsang National University, Jinju, 52828, Korea. Correspondence and requests for materials should be addressed to K.S.C. (email: chungks@gnu.ac.kr) 


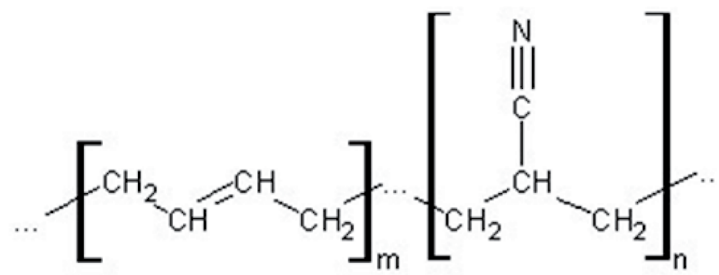

Butadiene

acrylonitrile

Figure 1. Molecular structure of the NBR copolymer of acrylonitrile and butadiene; m: number of butadiene moieties; n: number of acrylonitrile moieties.

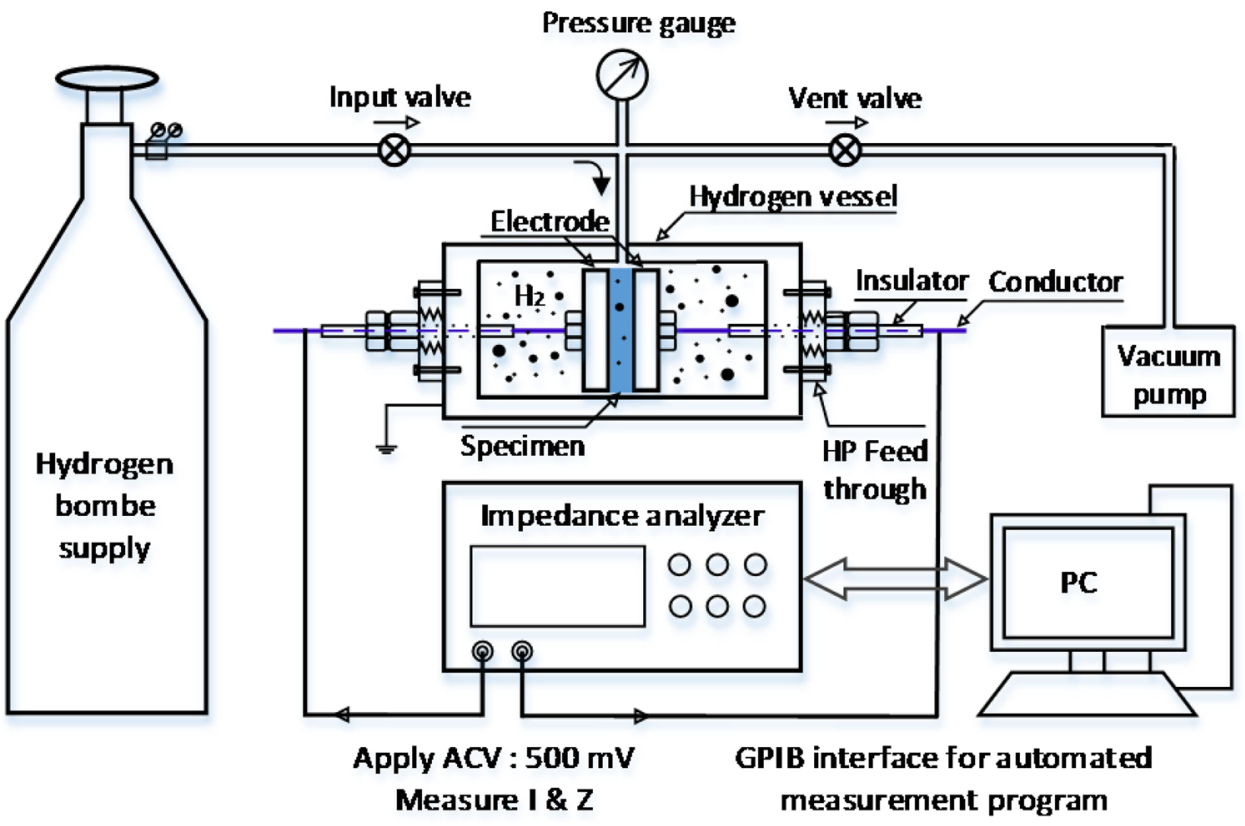

Figure 2. Configuration of the whole in situ impedance spectroscopy system under high-pressure $\mathrm{H}_{2}$.

\begin{tabular}{|l|l|}
\hline Chemical & Weight ratio (\%) \\
\hline NBR & 72 \\
\hline Carbon black & 22 \\
\hline Dicumyl peroxide & 1 \\
\hline ZnO & 2 \\
\hline Stearic acid & 1 \\
\hline Dioctyl adipate & 2 \\
\hline Total & 100 \\
\hline
\end{tabular}

Table 1. Chemical composition of the NBR specimen.

polymer during the processes of pressurization and decompression. The results of scanning electron microscopy (SEM) and a COMSOL simulation support the IS observations.

\section{Experimental}

Sample preparation. NBR (Fig. 1, Table 1) is a synthetic rubber copolymer of acrylonitrile and butadiene. NBR is widely used as a sealing material due to its excellent gas resistance. The NBR used in this study was synthesized by a Korean domestic company, and $22 \%$ carbon black was included as a filler during the fabrication of the NBR specimen. 


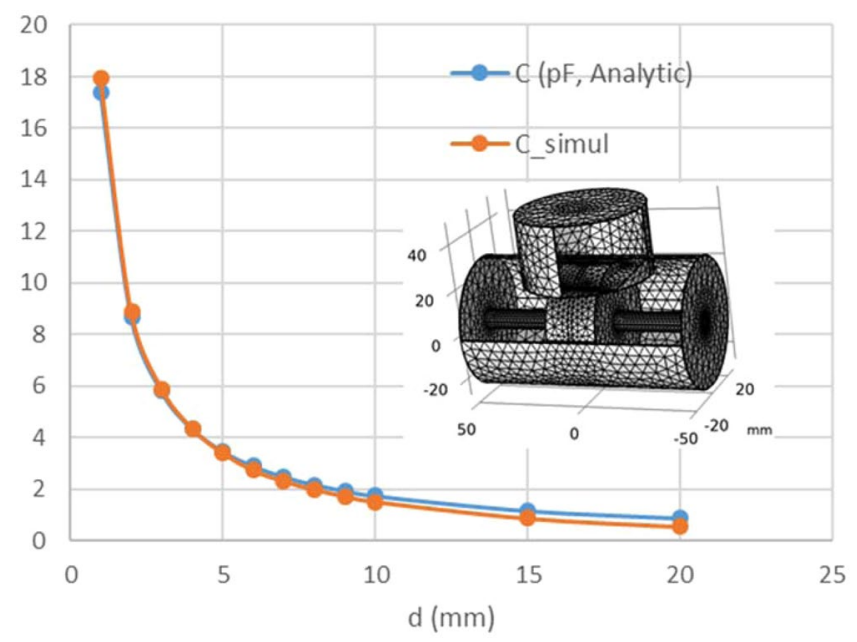

Figure 3. COMSOL software simulation results. Inset: the mesh structure of the modelled vessel. C_simul: COMSOL software simulation results; C_analytic: capacitance values predicted by an ideal parallel-plate model.

Impedance spectroscopy system. The IS system (Fig. 2) for the in situ measurement under high pressure comprises a hydrogen gas supply, input and vent valves, a pressure gauge, a hydrogen vessel, and an impedance analyser with a general purpose interface bus (GPIB) interface to a PC. The hydrogen vessel contains the specimen, electrodes and a high-pressure feed-through to withstand the seal at high pressure. The NBR used for this measurement was disc-shaped, $49 \mathrm{~mm}$ in diameter and $2 \mathrm{~mm}$ in thickness. The specimen was inserted between two electrodes and later fixed in place by mechanical pressure. The variation in the impedance of the specimen was monitored in real time using an Agilent $4294 \mathrm{~A}$ impedance analyser and an automated measurement program at the frequencies of the applied voltage of $40 \mathrm{~Hz} \leq$ frequency $\leq 10000 \mathrm{~Hz}$. The in situ capacitance $C_{\mathrm{NBR}}$ and DF $D F_{\mathrm{NBR}}$ were simultaneously measured as a function of pressure and exposure time for several days.

Thermal desorption analysis. Thermal desorption gas analysis (TDA) was performed using a 7890A analyser with a pulsed discharge detector from Agilent. To quantify the charged hydrogen content in the NBR, a specimen that had been exposed to $\mathrm{H}_{2}$ gas at $10 \mathrm{MPa}$ for $24 \mathrm{~h}$ was mounted in the tube furnace of the analyser. The specimen was $20 \mathrm{~mm}$ in diameter and $2 \mathrm{~mm}$ in thickness. The release of $\mathrm{H}_{2}$ gas was measured by gas chromatography every $5 \mathrm{~min}$ for the first hour and then at intervals of $1 \mathrm{~h}$ for $16 \mathrm{~h}$.

\section{Results and Discussion}

COMSOL simulation. To quantify the relationship between the measured $C_{\mathrm{NBR}}$ and the relative dielectric constant $\varepsilon_{\mathrm{r}}$ of the rubber, COMSOL software was used to model the hydrogen vessel and the electrodes (Fig. 3). The electric current conservation equations, $\boldsymbol{J}=\sigma \boldsymbol{E}+\boldsymbol{J}_{\mathrm{e}}, \boldsymbol{E}=-\boldsymbol{\nabla} V$, where $\boldsymbol{J}$ is the current density, $\sigma$ is the conductivity, $\boldsymbol{J}_{\mathrm{e}}$ is the external current density, $\boldsymbol{E}$ is the electric field, and $V$ is the electric potential, are solved with a boundary condition set by a ground domain at one electrode extending to the outer cylinder and a $1 \mathrm{~V}$ potential domain at the other electrode. A default mesh condition with a fine mesh size was used. The capacitance is equal to the total charge accumulated at the electrode, because we applied a unit potential of $1 \mathrm{~V}$. The charge was calculated by surface integration of the surface charge over the front and side faces of the counter electrode, including the centre rod. In order to simulate the grounded vessel, the surface charge integration was carried over the counter electrode only excluding the vessel. The COMSOL simulations (Fig. 3, C_simul) show the capacitance $C$ versus the electrode gap $d$. For $d<1 \mathrm{~mm}$, the $C_{-}$simul deviated from the capacitances ( $C_{-}$analytic) calculated using an ideal parallel-plate model, $C_{\mathrm{NBR}}=\varepsilon_{0} \cdot R^{2} / d$ (where $R$ is the radius of the parallel electrode face), because of the limits of the geometric precision in the mesh modelling. The deviation between $C_{-}$simul and $C_{\text {_analytic }}$ for $d>10 \mathrm{~mm}$ is attributed to a stray field that primarily forms between the side faces of the electrodes. It should be noted that the stray field between electrode faces and the inner faces of the vessel does not make any effect in capacitance because the vessel is electrically grounded. This is the main reason why the deviation for $d>10 \mathrm{~mm}$ is not very large. For high sensitivity and to avoid the stray field effect, we chose $d=2 \mathrm{~mm}$. Another simulation with the rubber inserted between the electrodes was performed by varying the relative dielectric constant of the rubber material for $d=2 \mathrm{~mm}$. The result was a simple linear relationship: $C_{\mathrm{NBR}}=0.31+8.22 \varepsilon_{\mathrm{r}}[\mathrm{pF}]$. The linear relationship is expected to be maintained for other values of $d$.

$\mathrm{H}_{2}$ effect on the impedance spectra. The effect of $\mathrm{H}_{2}$ on the spectra of $C_{\mathrm{NBR}}$ versus frequency for NBR in the sequential overall processes was quantified in three steps. (1) The $C_{\mathrm{NBR}}$ spectra versus frequency were measured before $\mathrm{H}_{2}$ pressurization (HP) (Fig. 4a). (2) The pressure was increased to $10 \mathrm{MPa}$ over $30 \mathrm{~min}$, and the $C_{\mathrm{NBR}}$ spectra versus frequency were subsequently measured after $\mathrm{HP}$ at $10 \mathrm{MPa}$ for $25 \mathrm{~h}$ (Fig. $4 \mathrm{~b}$; several lines overlay). (3) $\mathrm{H}_{2}$ decompression (HD) was conducted for $20 \mathrm{~min}$, and then the $C_{\mathrm{NBR}}$ spectra versus frequency were measured after HD for $30 \mathrm{~h}$ (Fig. 4c; several lines overlay). The capacitance decreased by more than an order of 

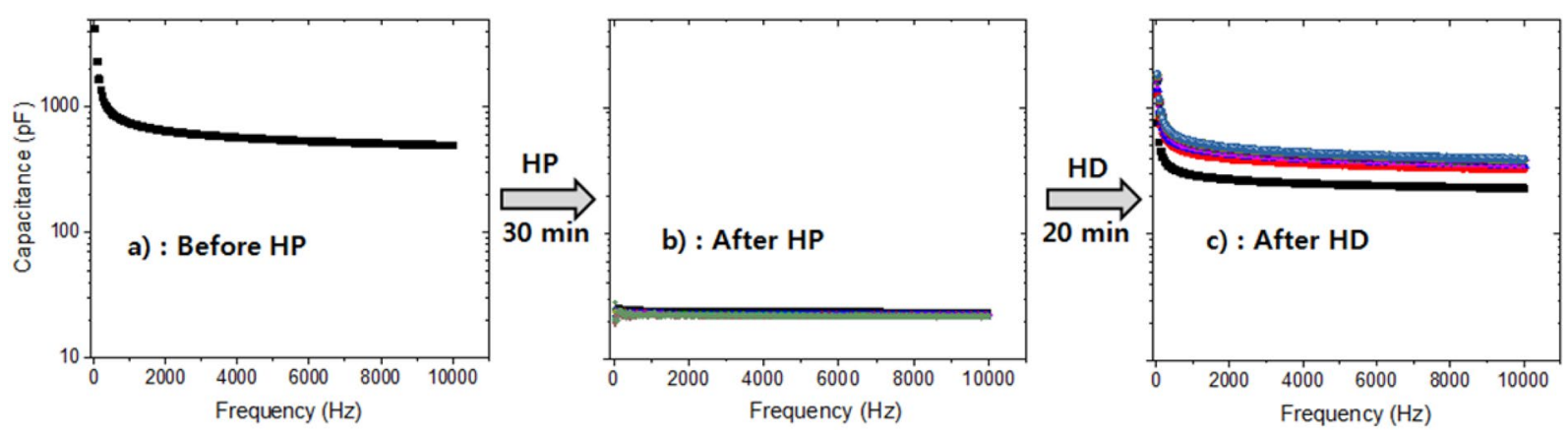

Figure 4. Effect of hydrogen on the capacitance spectra versus frequency for NBR: (a) before HP, (b) after HP, and (c) after HD. The logarithmic scale is the same in all figures.

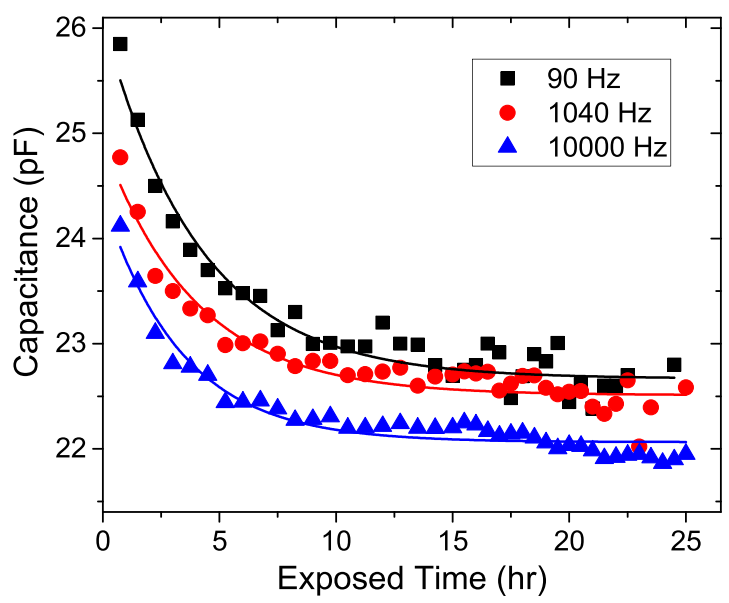

Figure 5. Capacitance decay measured at three different frequencies as a function of the exposure time during in situ hydrogen exposure at $10 \mathrm{MPa}$. The three solid lines are fitted with the equation $\mathrm{C}_{0} \cdot \exp \left(-\mathrm{A} D_{1} \mathrm{t}\right)$ at the corresponding frequency.

magnitude after $\mathrm{HP}$ and then recovered to almost its original value after $\mathrm{HD}$. The $D F_{\mathrm{NBR}}$ spectra versus frequency showed behaviour similar to that of the $C_{\mathrm{NBR}}$ spectra. The observed large change in both $C_{\mathrm{NBR}}$ and $D F_{\mathrm{NBR}}$ implies that IS responds very rapidly to pressurization and decompression and is therefore an appropriate tool for detecting the effects of $\mathrm{H}_{2}$.

The duration of exposure to $\mathrm{H}_{2}$ affected $C_{\mathrm{NBR}}$ (Fig. 5) at frequencies of 90, 1040, and 10,000 $\mathrm{Hz}$ during $\mathrm{H}_{2}$ exposure at a pressure of $10 \mathrm{MPa}$. Figure 5 is an enlargement of Fig. $4 \mathrm{~b}$ and shows $C_{\mathrm{NBR}}$ as a function of exposure time at the three frequencies. $C_{\mathrm{NBR}}$ decreased exponentially with increasing exposure time to $\mathrm{H}_{2}$; this trend is caused by the diffusion of $\mathrm{H}_{2}$ into the NBR. In many polymers, such diffusion of high-pressure $\mathrm{H}_{2}$ induces plasticization $^{13-15}$, which results in a reduction in the dielectric constant and capacitance. The decrease in the dielectric constant will be discussed later.

The change in the capacitance is expected only depend on the penetrated $\mathrm{H}_{2}$ content by assuming a first-order approximation. Thus, the evolution of the capacitance was affected by the diffusion-controlled process of $\mathrm{H}_{2}$. The content $\mathrm{c}(\mathrm{t})$ of $\mathrm{H}_{2}$ and the change in capacitance, which are the solutions of the diffusion equation, are expressed as follows ${ }^{11}$.

$$
\begin{aligned}
& c(t)=\frac{32}{\pi^{2}} c(0) \cdot\left[\sum_{n=0}^{\infty} \frac{\exp \left(-(2 n+1)^{2} \pi^{2} D t / z^{2}\right)}{(2 n+1)^{2}}\right] \cdot\left[\sum_{n=1}^{\infty} \frac{\exp \left(-D \beta_{n}^{2} t / r^{2}\right)}{\beta_{n}^{2}}\right] \\
& \approx \frac{32 c(0)}{5.8 \pi^{2}} \cdot \exp \left[-\left(\frac{\pi^{2}}{z^{2}}+\frac{5.8}{r^{2}}\right) D t\right]
\end{aligned}
$$

where $\mathrm{c}(\mathrm{t})$ is the hydrogen content at time $\mathrm{t}$ and $\mathrm{c}(0)$ is the equilibrium hydrogen content. $D$ is the diffusion coefficient (diffusivity) with a unit of $\left[\mathrm{m}^{2} / \mathrm{s}\right] . z$ and $r$ are the thickness and radius of the disc-shaped specimen, respectively. $\beta_{n}$ is the root of the zero-order Bessel function. We obtain the diffusion coefficient of $\mathrm{H}_{2}$ by fitting the data of the capacitance evolution to Eq. (1). The experimental data were well fitted to Eq. (1) by assuming a single-exponential decay of $C=C_{0} \cdot \exp \left(-\mathrm{A} D_{1} t\right)$ (Fig. 5, solid lines), where $\mathrm{C}_{0}$ is the capacitance at $t=0$, and $\mathrm{A}$ is 


\begin{tabular}{|l|l|l|}
\hline Freq. $(\mathbf{H z})$ & $\boldsymbol{D}_{\mathbf{1}}\left(\mathbf{1 0}^{\mathbf{- 1 1}} \mathbf{m}^{\mathbf{2}} / \mathbf{s}\right)$ & $\mathbf{D}_{\mathbf{2}}\left(\mathbf{1 0}^{-\mathbf{1 1}} \mathbf{m}^{\mathbf{2}} / \mathbf{s}\right)$ \\
\hline 90 & 3.1 & 2.4 \\
\hline 1040 & 3.3 & 2.9 \\
\hline 10000 & 3.4 & 3.1 \\
\hline
\end{tabular}

Table 2. Diffusion coefficients $D_{1}$ and $D_{2}$ for pressurization (Fig. 5) and decompression (Fig. 6), respectively, at three frequencies.

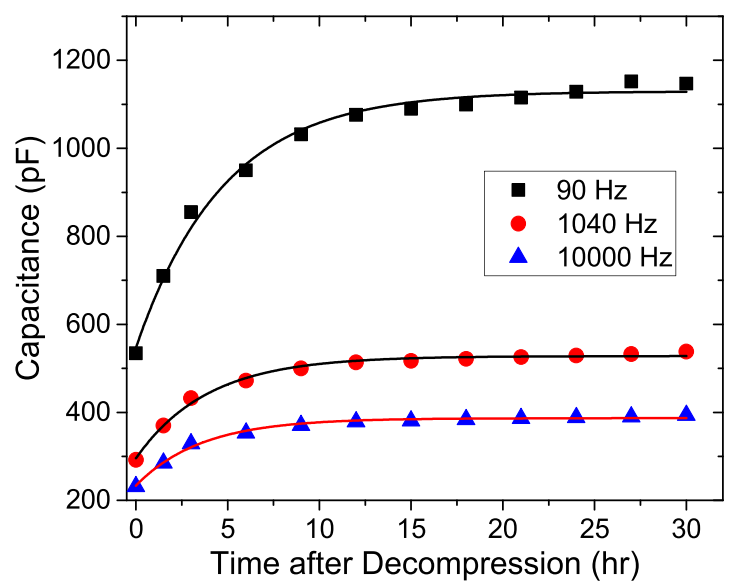

Figure 6. Capacitance recovery with time after decompression at a hydrogen pressure of $10 \mathrm{MPa}$. The three solid lines are the data fits to $C=C_{\infty} \cdot\left[1-\exp \left(-\mathrm{A} D_{2} t\right)\right]$ at each frequency.

a constant corresponding to $\left(\frac{\pi^{2}}{z^{2}}+\frac{5.8}{r^{2}}\right)$ with $z=2 \mathrm{~mm}$ and $r=24.5 \mathrm{~mm}$. The obtained value of $D_{1}$ is a diffusion coefficient that depends on frequency (Table 2) for the $\mathrm{H}_{2}$ penetration into the rubber.

Meanwhile, the recovery of the capacitance over time at atmospheric pressure after the decompression of the $\mathrm{H}_{2}$ pressure of $10 \mathrm{MPa}$ exhibited an exponential increase at all frequencies to maxima that decreased with increasing frequency (Fig. 6). Figure 6 is an enlargement of Fig. $4 \mathrm{c}$ and presents $C_{\mathrm{NBR}}$ versus time after decompression. The exponential increase over time is a result of $\mathrm{H}_{2}$ desorption from the rubber by deplasticization after the release of pressure. The evolution of the capacitance was also controlled by the diffusion process of $\mathrm{H}_{2}$. An exponential function $C=C_{\infty} \cdot\left[1-\exp \left(-\mathrm{A} D_{2} t\right)\right]$, where $\mathrm{C}_{\infty}$ is a saturated capacitance at infinite time, was also fitted to the data, and the diffusion coefficient $D_{2}$ for the $\mathrm{H}_{2}$ desorption from the rubber was already obtained (Table 2). Single-exponential growth was also assumed for this fit.

The diffusion of $\mathrm{H}_{2}$ into the rubber saturates at $\sim 12 \mathrm{~h}$ during pressurization (Fig. 5), and the clearance from the rubber during decompression takes $\sim 15 \mathrm{~h}$ (Fig. 6). $D_{2}$ is slightly larger than $D_{1}$; this difference implies that the $\mathrm{H}_{2}$ desorption is slower than the absorption; therefore, a hysteretic phenomenon occurs, possibly because $\mathrm{H}_{2}$ interacts with the polymer chains.

We have also measured the penetrated $\mathrm{H}_{2}$ content into NBR as a function of time using TDA ${ }^{11}$ and electronic balances. According to the results in two methods, it takes about $10 \mathrm{~h}$ for the $\mathrm{H}_{2}$ contents to reach the maximum. This is consistent with the capacitance measurement as shown in Fig. 5. Thus, we could say the long-term change in capacitance is due to slow diffusion of $\mathrm{H}_{2}$. The results for decompression of Fig. 6 also shows similar behavior. The temperature and relative humidity were maintained within $(23 \pm 2)^{\circ} \mathrm{C}$ and $(50 \pm 5) \%$, respectively, in national calibration laboratory. The long-term drift effect on impedance analyser 4294A for several hours with a fresh specimen without $\mathrm{H}_{2}$ penetration was found to be negligible, which was less than approximately $3 \%$ of measured value. Therefore, the additional effects except of $\mathrm{H}_{2}$ was not included in the measurement.

$C_{\mathrm{NBR}}$ (Fig. 6) was transformed to the imaginary part of the impedance, $Z_{\mathrm{im}}=1 /(\omega C)$ for a comparison with the TDA data. To find a correlation between IS and TDA, $Z_{\text {im }}$ normalized by $C_{\infty}$ was compared with the normalized $\mathrm{H}_{2}$ content obtained by TDA (Fig. 7). The two results were consistent overall, which implies again that the change in $Z_{\text {im }}$ is directly related to the desorbed $\mathrm{H}_{2}$ content. Such consistency is compatible with previous results obtained with TDA and $\mathrm{NMR}^{16}$. However, the IS data show a slower desorption of $\mathrm{H}_{2}$ than the TDA data (Fig. 7). Although there are unique measurement conditions with different dimensions in both of the specimens, this difference implies that the physics of the dependence of the impedance on the hydrogen content is different from that of the hydrogen diffusion process in the specimen. The TDA measurement only detects the hydrogen content released through the diffusion process. In addition to the effect of the released hydrogen content, IS is also affected by the chemical/physical interaction of hydrogen with the rubber polymer. Furthermore, the IS results may also due to the slow relaxation, i.e., the pressurization-induced state of the polymer matrix, or the fact that the filler distribution slowly relaxes towards another equilibrium and can continue to relax even after all the free $\mathrm{H}_{2}$ molecules are released during decompression. The relaxation may be irreversible; therefore, the original status cannot be recovered. 


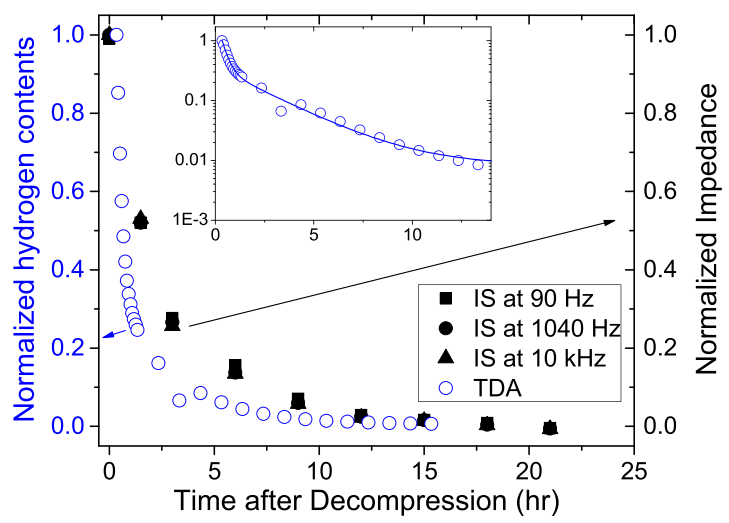

Figure 7. Comparison between the hydrogen content profile with time after decompression at a $\mathrm{H}_{2}$ pressure of $10 \mathrm{MPa}$ measured by IS and TDA. Inset: exponential fitting (Solid Line) for the log-transformed data of the normalized hydrogen content.
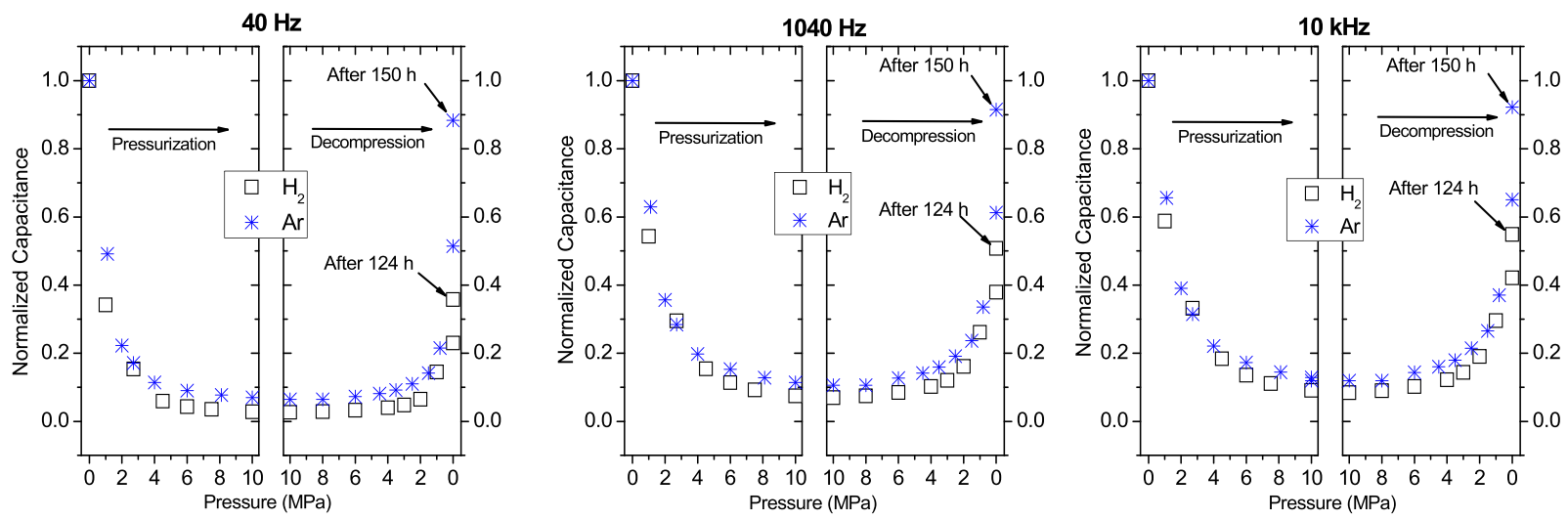

Figure 8. Change in the normalized capacitance with pressure in the pressurization and decompression processes under high-pressure hydrogen $(\Upsilon)$ and argon $(*)$ gases at three frequencies.
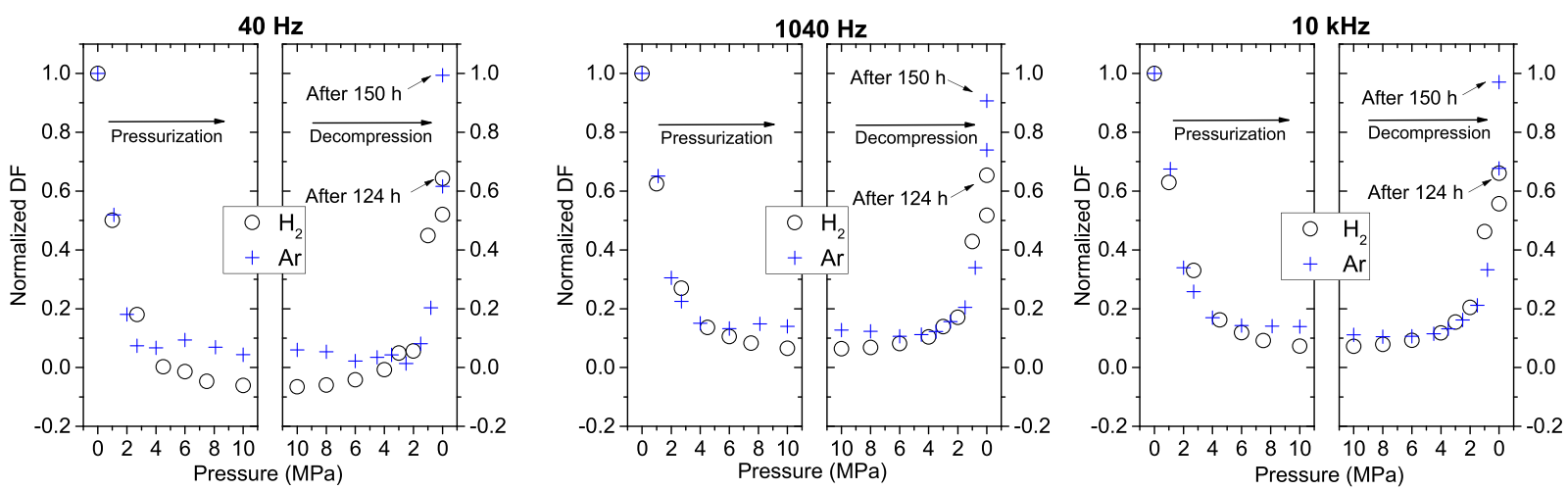

Figure 9. Change in the normalized DF with pressure in the pressurization and decompression processes under high-pressure hydrogen $(O)$ and argon $(+)$ gases at three frequencies.

The TDA experimental data (Fig. 7) could not be fitted well with a single exponential function; therefore, a two-exponential fit on the basis of Eq. (1) was employed (Fig. 7, inset), $\exp \left(-\mathrm{B} D_{2, \mathrm{f}} \mathrm{t}\right)+\exp \left(-\mathrm{B} D_{2, \mathrm{~s}} \mathrm{t}\right)$, where $\mathrm{B}$ is a constant corresponding to $\left(\frac{\pi^{2}}{z^{2}}+\frac{5.8}{r^{2}}\right)$ with $z=2 \mathrm{~mm}$ and $r=10 \mathrm{~mm} . D_{2, \mathrm{f}}$ and $D_{2, \mathrm{~s}}$ are fast and slow diffusion coefficients, respectively. The behaviour in the TDA data may arise from two kinds of diffusion processes for $\mathrm{H}_{2}$ : a fast process (left side in the inset) for $\mathrm{H}_{2}$ in the polymer network matrix and a slow process (right side slope in the inset) from $\mathrm{H}_{2}$ in the filler (carbon black). $D_{2, \mathrm{f}}$ and $D_{2, \mathrm{~s}}$ were found to be $3.9 \times 10^{-10} \mathrm{~m}^{2} / \mathrm{s}$ and $4.2 \times 10^{-11} \mathrm{~m}^{2} / \mathrm{s}$, respectively. 


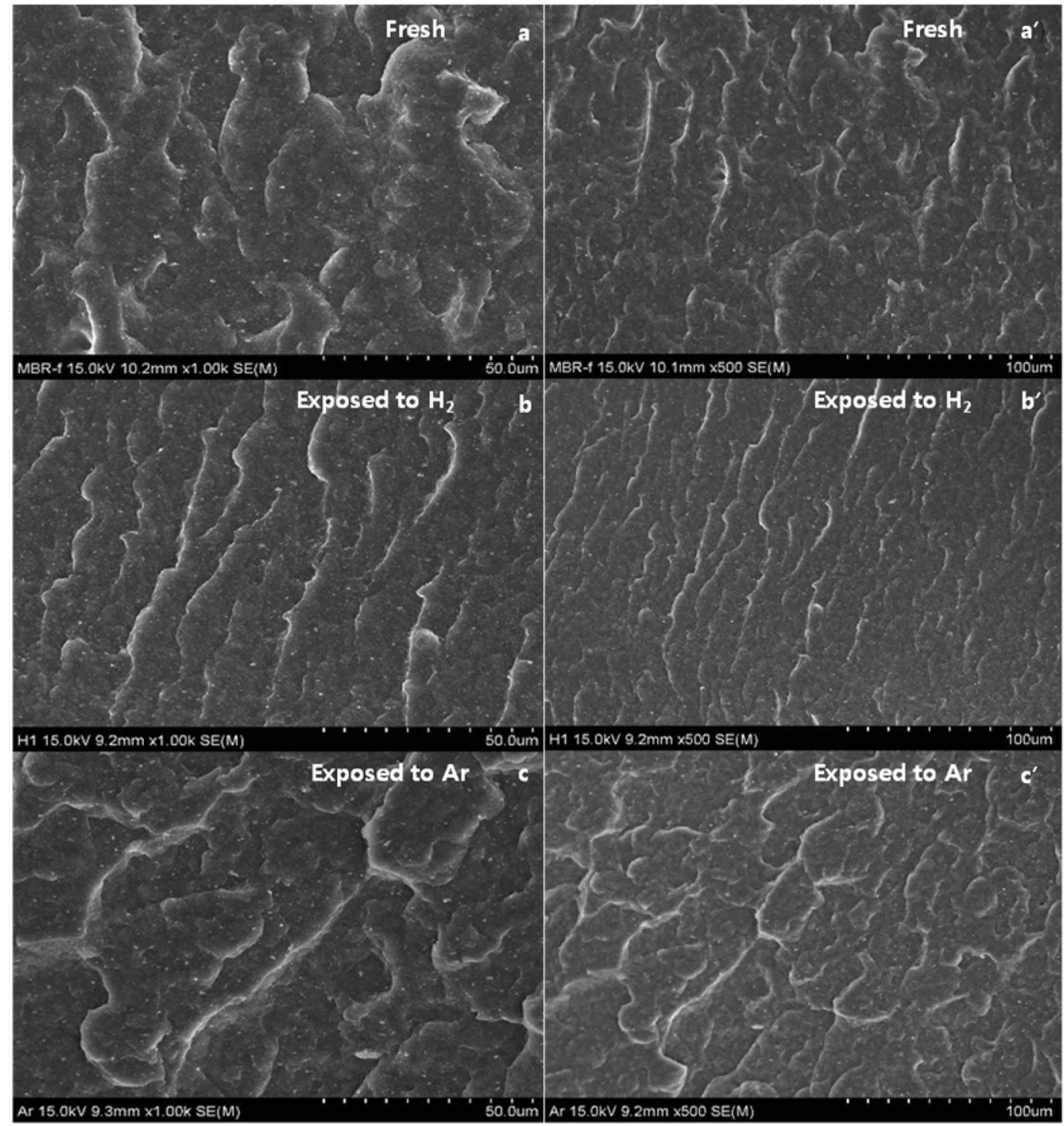

Figure 10. SEM images of the fresh NBR (a,a') without exposure to hydrogen, NBR (b,b') exposed to $\mathrm{H}_{2}$ at $10 \mathrm{MPa}$ and $\mathrm{NBR}\left(\mathbf{c}, \mathbf{c}^{\prime}\right)$ exposed to Ar at $10 \mathrm{MPa}$. Left column: image sequences obtained from the same spot; scale bar $=50 \mu \mathrm{m}$. Right column: sequences obtained from the same spot at a higher magnification; scale bar $=100 \mu \mathrm{m}$.

The normalized capacitance $C_{\text {nor }}$ was also obtained during cyclic pressurization and decompression under $\mathrm{H}_{2}$ and Ar gases (Fig. 8). The pressure dependences of $C_{\text {nor }}$ were similar at all three frequencies. $C_{\text {nor }}$ decreased exponentially as the pressure increased during pressurization and later increased as the pressure decreased during decompression. The behaviours are very similar to those of $C_{\mathrm{NBR}}$ versus time (Figs 5 and 6 ).

The large change in the dielectric constant of the rubber at the low frequency of $40 \mathrm{~Hz}$ under high-pressure $\mathrm{H}_{2}$ (Fig. 8) can be explained by a change in the polarizability of the polymer chain matrix and the fillers, because the $\mathrm{H}_{2}$ in the rubber region contributes little to the total polarization. The strong frequency dependence of the dielectric constant of the rubber at the low frequency is explained by the polarization arising from the displacement or rotation of the fillers that have a net charge or a net dipole moment in the interface region around the fillers due to the interfacial polarization known as the Maxwell-Wagner-Sillars effect ${ }^{17,18}$.

The decrease in the dielectric constant with the exposure to high-pressure ambient $\mathrm{H}_{2}$ is expected, because the degrees of freedom of the polymer chain and the fillers decrease as the gas molecules occupy more space. A similar phenomenon was observed by pressurizing with Ar gas (Fig. 8).

According to the COMSOL simulation result $C_{\mathrm{NBR}}=0.31+8.22 \varepsilon_{\mathrm{r}}$, the relative dielectric constant $\varepsilon_{\mathrm{r}}$ of the rubber sample at a pressure $>5 \mathrm{MPa}$ was found to be $\sim 3$, which has also been observed in silicon dioxide ${ }^{19}$ and many rigid plastic materials, such as epoxy glass ${ }^{20}$ and Bakelite ${ }^{21}$. A dielectric constant $(\sim 3)$ smaller than the value in a normal rubber polymer suggests that the decrease in the dielectric constant may occur because, due to the solvent, $\mathrm{H}_{2}$ causes the formation of a rigid plastic phase or a glass phase. This finding suggests that the penetration of high-pressure $\mathrm{H}_{2}$ with a low molecular mass in the process of pressurization, which generally induces 
plasticization for many polymers ${ }^{13-15}$, resulted in a reduction in the dielectric constant and capacitance of the polymers, whereas the increase in $C_{\text {nor }}$ during decompression (Fig. 6) was caused by deplasticization after the release of pressure.

The normalized $D F_{\mathrm{NBR}}$ was also affected by the pressure during both pressurization and decompression under both $\mathrm{H}_{2}$ and Ar gases at all three frequencies (Fig. 9). The behaviour was similar to that of $C_{\text {nor }}$ under $\mathrm{H}_{2}$ and $\mathrm{Ar}$ gases. The measurement time for Figs 8 and 9 is about $2 \mathrm{~h}$ in the process of the pressurization and decompression. In Fig. 9, normalized dissipation factor (DF) value at $40 \mathrm{~Hz}$ is -0.06 , for the capacitance of $25 \mathrm{pF}$ in Fig. 8 . In the case with the value of lowest frequency of $40 \mathrm{~Hz}$ and small capacitance under the applied AC voltage of $0.5 \mathrm{~V}$, the magnitude of the measured DF is regarded as very small, because the $40 \mathrm{~Hz}$ is the lowest limit of the impedance analyzer 4294 A used and the manufacturer's specification ${ }^{22}$ say the uncertainty of DF at this frequency and capacitance level amounts to $10 \%$. Thus, the measured DF is virtually regarded as zero and the negative sign is attributed to the measuring instrument having large uncertainty of DF at low frequency of $40 \mathrm{~Hz}$. However, with increasing the frequency, the uncertainty decreases.

The normalized $C_{\mathrm{NBR}}$ and normalized $D F_{\mathrm{NBR}}$ were affected more in $\mathrm{H}_{2}$ than in Ar during cyclic pressurization and decompression under the same pressure conditions (Figs 8 and 9). This difference implies that $\mathrm{H}_{2}$ has a greater permeation capability than Ar, possibly because of the molecular mass of $\mathrm{H}_{2}$. The most remarkable difference between $\mathrm{H}_{2}$ and Ar was that the recovery of the dielectric constant and the DF after decompression was considerably lower under $\mathrm{H}_{2}$ than under $\mathrm{Ar}$ (Figs 8 and 9). After $124 \mathrm{~h}$ of decompression in $\mathrm{H}_{2}$, the capacitance and the DF recovered to $40 \sim 60 \%$ of the initial values, whereas after $150 \mathrm{~h}$ of release in Ar, the rubber polymer recovered to $90 \sim 100 \%$ of the initial capacitance and DF. This failure to recover completely implies that $\mathrm{H}_{2}$ reacts chemically with the polymer and causes voids, defects, and a scission of the polymer chain, whereas inert Ar gas only causes a scission of the polymer. The SEM results partially support these findings, but further analysis is required.

SEM results. SEM images (Fig. 10) were obtained from the NBR without exposure to $\mathrm{H}_{2}$ and the NBR specimens exposed to $\mathrm{H}_{2}$ and $\mathrm{Ar}$ at $10 \mathrm{MPa}$. After exposure to $\mathrm{H}_{2}$, the morphology of the NBR (b, b') changed from a random distribution to a uniaxial directed distribution. One possibility is that percolated channelling between low-density regions occurs during the permeation of $\mathrm{H}_{2}$ gas under $10 \mathrm{MPa}$ of ambient pressure stress and causes a density modulation. In this instance, the distance between the valleys is $\sim 10 \mu \mathrm{m}$. The NBR specimen exposed to $\operatorname{Ar}\left(c, c^{\prime}\right)$ was modified to a circular type of modulation, which is reminiscent of a swollen balloon under gas injection instead of uniaxial channelling. The morphology of the Ar-exposed NBR reveals an Amoeba-like circle without any directional preference. These results demonstrate that different types of gases can result in different morphological responses at the same pressure. Thus we think it causes percolated channelling to an uniaxial directed distribution due to greater permeation than that exposed to Ar. Consequently, $\mathrm{H}_{2}$ effect on NBR are consistent with that already proposed by IS in views of greater permeation capability, stronger effects on physically and chemically in $\mathrm{H}_{2}$ more than Ar.

\section{Conclusions}

This paper presents the development and evaluation of an IS system to measure the effects of high-pressure $\mathrm{H}_{2}$ gas on rubber polymers. The in situ capacitance measurement enables the observation of the correlation between macroscopic and microscopic phenomena under high pressure. The developed IS system could be used as an in situ probe to gather information such as diffusivity in $\mathrm{H}_{2}$ diffusion and desorption processes in rubber polymers.

Although there is a difference in the time evolutions between IS and TDA, the results of this study indicate that IS may be a useful probe to observe real-time and in situ changes in the $\mathrm{H}_{2}$ content with time and pressure during pressurization and subsequent decomposition and could supplement the ex situ TDA method and other methods. The proposed IS system could also clarify in situ the effect of the permeation properties of a gas as a function of time and pressure in rubber during sequential pressurization and decompression processes.

\section{References}

1. Züttel, A., Borgschulte, A. \& Schlapbach, L. Hydrogen as a future energy carrier (ed. Züttel, A. et al.) 1-5 (Wiley-VCH Verlag $\mathrm{GmbH}, 2008)$.

2. Ball, M. \& Weeda, M. The hydrogen economy - vision or reality? Int. J. Hydrog. Energy 40, 7903-7919 (2015).

3. Mazloomi, K. \& Gomes, C. Hydrogen as an energy carrier: prospects and challenges. Renew. Sustain. Energy Rev. 16, 3024-3033 (2012).

4. Marchi, C. W. \& Somerday, B. P. Technical reference for hydrogen compatibility of materials. Sandia National Laboratories, http:// www.sandia.gov/matlsTechRef (2008)

5. Gangloff, R. \& Somerday, B. Gaseous hydrogen embrittlement of materials in energy technologies: the problem, its characterisation and effects on particular alloy classes. (ed. Gangloff, R. et al.) 51-90 (Woodhead Publishing, 2012).

6. Song, J. \& Curtin, W. A. Atomic mechanism and prediction of hydrogen embrittlement in iron. Nat. Mater. 12, 145-151 (2013).

7. Louthan, M. R., Caskey, G. R., Donovan, J. A. \& Rawl, D. E. Hydrogen embrittlement of metals. Mater. Sci. Eng. 10, 357-368 (1972).

8. Murakami, Y., Kanezaki, T., Mine, Y. \& Matsuoka, S. Hydrogen embrittlement mechanism in fatigue of austenitic stainless steels. Metall. Mater. Trans. 39A, 1327-1339 (2008).

9. Barth, R. R., Simmons, K. L. \& Marchi, C. S. Polymers for hydrogen infrastructure and vehicle fuel systems: applications, properties, and gap analysis. Sandia National Laboratories, Sandia Report, Online ordering at, http://www.osti.gov/bridge (2013).

10. Nishimura, S. International symposium of hydrogen polymers team, HYDROGENIUS, Kyushu University, http://hydrogenius. kyushu-u.ac.jp/ci/event/ihdf2017/pdf/prg-polver170111.pdf (2017).

11. Yamabe, J. \& Nishimura, S. Influence of fillers on hydrogen penetration properties and blister fracture of rubber composites for O-ring exposed to high-pressure hydrogen gas. Int. J. Hydrog. Energy 34, 1977-1989 (2009).

12. Yamabe, J., Matsumoto, T. \& Nishimura, S. Application of acoustic emission method to detection of internal fracture of sealing rubber material by high-pressure hydrogen decompression. Polym. Test. 30, 76-85 (2011).

13. Chen, X., Feng, J. J. \& Bertelo, C. A. Plasticization effects on bubble growth during polymer foaming. Polym. Eng. Sci. 46, 97-107 (2006). 
14. Bos, A., Pünt, I. G. M., Wessling, M. \& Strathmann, H. $\mathrm{CO}_{2}$-induced plasticization phenomena in glassy polymers. J. Membr. Sci. 155 , 67-78 (1999).

15. Alessi, P., Cortesi, A., Kikic, I. \& Vecchione, F. Plasticization of polymers with supercritical carbon dioxide: experimental determination of glass-transition temperatures. J. Appl. Polym. Sci. 88, 2189-2193 (2003).

16. Nishimura, S. \& Fujiwara, H. Detection of hydrogen dissolved in acrylonitrile butadiene rubber by ${ }^{1} \mathrm{H}$ nuclear magnetic resonance. Chem. Phys. Lett. 522, 43-45 (2012).

17. Mohanraj, G. T., Chaki, T. K., Chakraborty, A. \& Khastgir, D. Measurement of AC conductivity and dielectric properties of flexible conductive styrene-butadiene rubber-carbon black composites. J. Appl. Polym. Sci. 104, 986-995 (2007).

18. Samet, M. et al. Electrode polarization vs. maxwell-wagner-sillars interfacial polarization in dielectric spectra of materials: characteristic frequencies and scaling laws. J. Chem. Phys. 142, 194703, https://doi.org/10.1063/1.4919877 (2015).

19. Gray, P. R., Hurst, P. J., Meyer, R. G. \& Lewis, S. H. Analysis and design of analog integrated circuits. (ed. Vargas, V. A.) 40 (Wiley, 2009).

20. Sokolov, V. I., Shalgunov, S. I., Gurtovnik, I. G., Mikheeva, L. G. \& Simonov-Emel'yanov, I. D. Dielectric characteristics of glass fi bre reinforced plastics and their components. Int. Polym. Sci. Tech. 32, 62-67 (2005).

21. IFM Relative dielectric constants, table of dielectric constants of substances, https://www.ifm.com/img/dialectric_constants.pdf, http://www.ydic.co.jp/english/technology/table_E.html.

22. Agilent Technologies, Agilent 4294A Precision Impedance Analyzer Operation Manual Seventh Edition, Part No. 04294-90060, Chap. 10, 341-343 (2003).

\section{Acknowledgements}

This research was supported by Development of Reliability Measurement \& Standard Technology for Hydrogen Fueling Station funded by Korea Research Institute of Standards and Science (KRISS - 2019 - GP2019-0012).

\section{Author Contributions}

J.K. Jung have made a substantial contribution in the design of this work and analysis. S.K. Jeon made a contribution in the experiments of the hydrogen charging and impedance spectroscopy. K.T. Kim made a contribution in the COMSOL simulation. C.H. Lee made a contribution in the interpretation of SEM result. U.B. Baek made a contribution in the creation of new idea for this work. K.S. Chung made a contribution in the automatic program for real-time measurement of impedance.

\section{Additional Information}

Competing Interests: The authors declare no competing interests.

Publisher's note: Springer Nature remains neutral with regard to jurisdictional claims in published maps and institutional affiliations.

(c) (i) Open Access This article is licensed under a Creative Commons Attribution 4.0 International License, which permits use, sharing, adaptation, distribution and reproduction in any medium or format, as long as you give appropriate credit to the original author(s) and the source, provide a link to the Creative Commons license, and indicate if changes were made. The images or other third party material in this article are included in the article's Creative Commons license, unless indicated otherwise in a credit line to the material. If material is not included in the article's Creative Commons license and your intended use is not permitted by statutory regulation or exceeds the permitted use, you will need to obtain permission directly from the copyright holder. To view a copy of this license, visit http://creativecommons.org/licenses/by/4.0/.

(C) The Author(s) 2019 